\title{
Washability Characteristics of Low Volatile Pakistani Coking Coal by Crushing
}

\author{
Fahad Mir \\ Department of Chemical Engineering Technology, Yanbu Industrial College, \\ Yanbu Industrial City, KSA \\ Email: abdulhameedf@rcyci.edu.sa
}

Received 6 August 2014; revised 10 September 2014; accepted 18 September 2014

Copyright (C) 2014 by author and Scientific Research Publishing Inc.

This work is licensed under the Creative Commons Attribution International License (CC BY). http://creativecommons.org/licenses/by/4.0/

(C) (j) Open Access

\begin{abstract}
Through washability study, a couple of parameters were investigated for a low volatile Pakistani Coal (coking). The aim was to find out the effect of the action of reducing material release characteristics for low volatile Pakistani coal. The "Index of washability" (IW) and "Near gravity material Index" (NGMI) were used as parameters to express the ease of washability. Run of Mine coal is crushed to four different sizes as mentioned $80 \mathrm{~mm}, 30 \mathrm{~mm}, 18 \mathrm{~mm}$ and $11 \mathrm{~mm}$ in a pestle and mortar. Calculations of IW show that it is inversely proportional to top size of feed, indicating that washability increases with the decrease of size. From NGMI calculations it was concluded that gravity method is not recommended for separation at this specific gravity range. So study divulges that the critical specific gravity for crushing to $30 \mathrm{~mm}$ is 1.67 and for $11 \mathrm{~mm}$ is 1.56 .
\end{abstract}

\section{Keywords}

Low Volatile, Pakistani Coal, Gravity Index, Run of Mine, Coal

\section{Introduction}

The washability of coal or minerals is expressed by a curve or graph showing the results of a series of float-andsink tests [1]. A low grade coal is a coal which contains impurities which on burning pollute the environment, and has calcite, pyrite, silica, sulphates, $\mathrm{CaCO}_{3}$, and sulphates of $\mathrm{CaCO}_{3}$, sulphates from oxides as components which form complexes after reacting with other materials. It tends to form coal ash. These coals are characterized by high ash content and are difficult in cleaning potential [2]. Also, it contains sulphates which tend to decrease its clinkering temperature and various coals cleaning methods depending on the physical property difference which is quite different in their specific gravity or wetting characteristics. These important parameters are to be analyzed as Pakistani coal can generate $100 \mathrm{GW}$ electricity for upcoming years [3]. 
Conventional coal washability information is generally obtained in the laboratory by the tedious sink-float analysis using hazardous halogenated organic compounds in large quantities [4]. Best possible crushing of the coal results in large amount of liberation so that the combustibles can be easily separated. The process used is gravity separation methods [5]. It is quite suitable to carry out the sink-float analysis of the coal to estimate its persuasion towards gravity concentration methods. "Washability Curves" are been made from the data obtained from Sink-float analysis to obtain helpful information regarding clean coal that can be obtained from a given coal under ideal conditions [6].

\section{Materials and Methods}

Representative ROM (Run of Mine) coal samples (feed ash 35.69\%) from Pakistan Mineral Development Corporation from four different coal mines (Pakistan) were studied in the present investigation. Selected coals which are free from visible lumps were used for sink float analysis in order to avoid mineral matter addition. The sample was crushed in pestle and mortar at four different sizes which were $80 \mathrm{~mm}, 30 \mathrm{~mm}, 18 \mathrm{~mm}$ and 11 $\mathrm{mm}$ in top size levels and were screens through vibrating shaking screens as size wise. For each of the top size level sink and float tests were carried out by using bromofrom, benzene and zinc-chloride solutions. Those solutions were used as heavy media at different specific gravities.

The amount of material floating at a particular specific gravity can be theoretically measured as the recovery of two constituents, could be non-ash and ash forming materials, however because the ash material in used coal is easily washable and contains property to liberate complexly but completely from ash material. The aim was to recover all non-ash material (present in the feed) without recovering ash material in the clean coal. On the other hand it was quite difficult to handle (DTW) difficult to wash coal which have lack of ash material (AM) and non-ash (NA) content cannot be reduced by a treatment to improve its properties. Two terms, washability index and washability number, have been selected to count the approachability of given coal towards washing. Various mathematical expressions are developed to calculate the "Index of washability (IW)" and "Near gravity material index (NGMI)" respectively. The values of "Index of washability (IW)" vary from 0 to 100 for the difficult to wash DTW to easy to wash ETW. The values of "Near gravity material index (NGMI)" vary from 0 to 1 for the ETW to DTW.

\section{Results and Discussion}

The experimental results of four Pakistani Coals at different specific gravity with respect to different crushing size are shown in Table 1. The sizes are $80 \mathrm{~mm}, 30 \mathrm{~mm}, 18 \mathrm{~mm}$ and $11 \mathrm{~mm}$. At different particle size ash weight and ash percentages are evaluated with specific range to obtain accuracy in results and investigations. By decreasing the particle size decrease of weight percentage can be seen at $80 \mathrm{~mm}$ crushed size, plus the change in ash percentage is also gradual. If we compare the weight percentage for $80 \mathrm{~mm}, 18 \mathrm{~mm}$ and $11 \mathrm{~mm}$ at point $3+$ 0.5 , they were $6.7,21.1$ and 23.3 respectively which shows continuous increase by decrease of crushing size. But the case is not similar for ash percentage.

Table 1. Size wise investigation of Pakistani coal at special crushing size levels.

\begin{tabular}{|c|c|c|c|c|c|c|c|c|c|c|c|}
\hline \multicolumn{3}{|c|}{ Crushed to below $80 \mathrm{~mm}$ size level } & \multicolumn{3}{|c|}{ Crushed to below $30 \mathrm{~mm}$ size level } & \multicolumn{6}{|c|}{ Crushed to below $18 \mathrm{~mm}$ size level Crushed to below $11 \mathrm{~mm}$ size level } \\
\hline Particle size mm & Wt \% & Ash \% & Particle size mm & Wt \% & Ash \% & Particle size mm & Wt \% & Ash \% & Particle size mm & Wt \% & Ash \% \\
\hline$-55+30$ & 33.2 & 38.9 & $-30+18$ & 23.4 & 33.3 & $-11+8$ & 20.2 & 32.4 & $-8+3$ & 33.9 & 32.9 \\
\hline$-30+18$ & 14.3 & 37.7 & $-18+11$ & 15.8 & 37.5 & $-8+3$ & 26.1 & 30.9 & $3+0.5$ & 23.3 & 26.2 \\
\hline$-18+11$ & 8.4 & 35.8 & $-11+8$ & 23.6 & 36.3 & $3+0.5$ & 21.1 & 28.8 & & & \\
\hline$-11+8$ & 5.7 & 37.1 & $-8+3$ & 19.2 & 32.8 & & & & & & \\
\hline$-8+3$ & 8.4 & 33.3 & $3+0.5$ & & & & & & & & \\
\hline$-3+0.5$ & 6.7 & 29.1 & & & & & & & & & \\
\hline
\end{tabular}


On the basis of specific assumption that recovery is an incessant function of growing fractional weight of feed coal floated, the recovery curves for non-ash and ash materials has been drawn for the calculation of washability Index, IW.

With the help of obtained data from investigation the washability curves have been drawn. Cumulative ash percentage is placed on $\mathrm{y}$ axis and cumulative yield percentage on $\mathrm{x}$ axis as shown in Figure 1. Cumulative yield percentage is from 10 - 100 while cumulative ash percentage is from 10 to 35 . Here Cumulative yield percentage is gradually increasing with the increase of cumulative ash \% and show the maximum limits

$I W=$ Efficiency of recovery of non-ash material $*$ Differences in recoveries of ash and non-ash materials $\times 100 / 3$

With the help of above mentioned equation Index of Washability is projected at sizes dissimilarity table is generated which clearly shows that the decrease in size is inversely proportional to increase in washability. So lowering the size of crushing coal will definitely enhance the washability. Table 2 indicates that lowering the size of crushing will definitely improve the coal benefits and can be very economical. As lowering up to $11 \mathrm{~mm}$ is having nice impact over results as compared to other sizes. Here Figure 2 shows curves of two different colors red and black represents the recovery for non-ash and ash forming materials.

Trend study of the analysis among specific gravity and near gravity material index (NGMI) at different top crushed sizes been made with different points and trends shown in Figure 3. At different points of specific gravity the trends are showing variety of readings. However all the trends are started from 1.4 and ended at 2.0. The maximum NGMI trend is 0.32 at 1.75 . Common point was taken to elaborate the investigation further. At specific gravity 1.8 random behaviors of trends (at different crushed sizes) seen that are 0.375, 0.12, 1.10 and 0.05 for $-80 \mathrm{~mm},-30 \mathrm{~mm},-18 \mathrm{~mm}$ and $-11 \mathrm{~mm}$ respectively. Discernible decrease can be noticed here at $y$ axis in (NGMI) in Figure 3.

When the value of NGMI is high it shows that the critical specific gravity played its part. Figure 4 explains that the values of coal at different sizes are sizes effects the specific gravity value and curves shows it very well

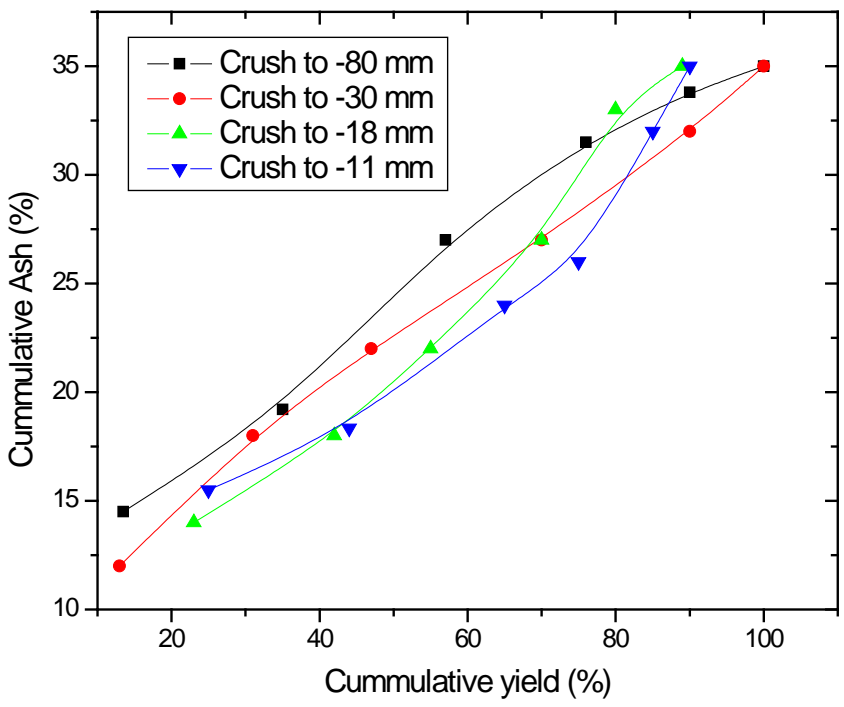

Figure 1. Washability curves for coal crushed to different top sizes.

Table 2. The value of Index of washability at different crushing sizes.

\begin{tabular}{cc}
\hline Type of coal & Value of IW (calculation based) \\
\hline Crushed to $-80 \mathrm{~mm}$ & 30.9 \\
Crushed to $-30 \mathrm{~mm}$ & 31.9 \\
Crushed to $-18 \mathrm{~mm}$ & 34.0 \\
Crushed to $-11 \mathrm{~mm}$ & 41.4 \\
\hline
\end{tabular}




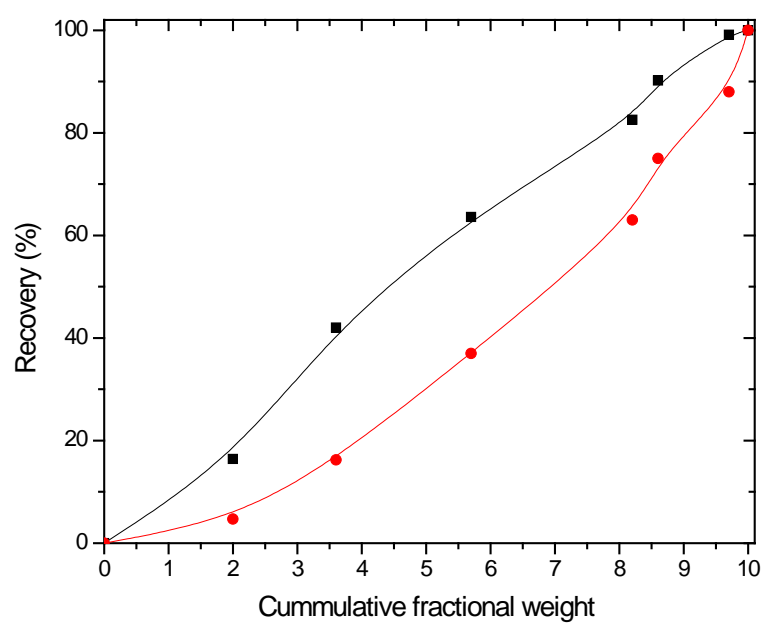

Figure 2. Two curves (hypothetically calculated) are shown represents the recovery of non-ash and ash forming materials.

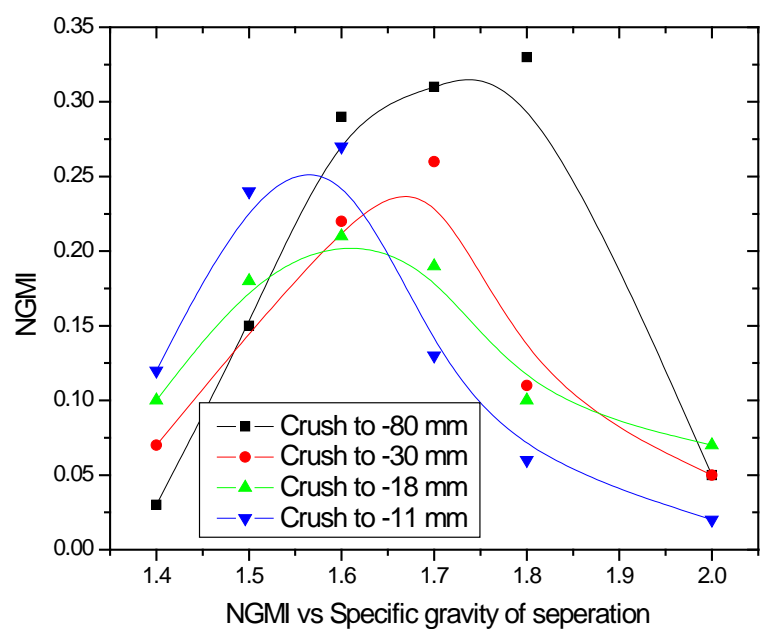

Figure 3. Trends showing the analysis among specific gravity vs. near gravity material index at different top crushed sizes.

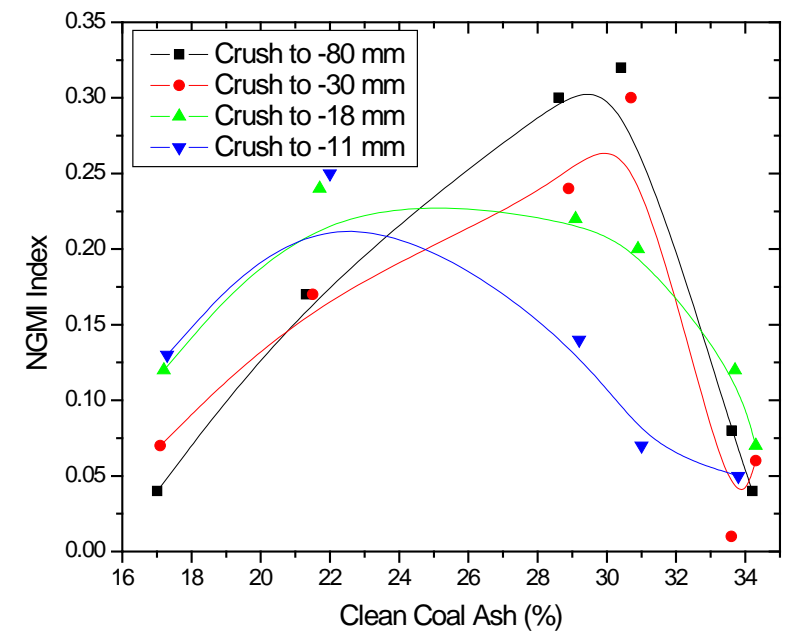

Figure 4. Trends showing point's analysis and the curves (trends) for near gravity material index vs clean coal ash \%. 
e.g., the value of critical specific gravity at $30 \mathrm{~mm}$ is 1.67 and for $11 \mathrm{~mm}$ is 1.56 which shows that at these values of specific gravities the separation is very difficult even by using gravity method. So keeping this in mind the suggestion is to use Washability index and NGMI could be more useful plus it will help to determine the size of run of Mine coal and with the same difficulty level clean coal with very less ash percentage can be produced from 2 or more crushing sizes.

\section{Conclusions}

This study divulges that Near Gravity Material Index and washability index might be functional to estimate the ease of beneficiation of coal using gravity methods. Index of washability can determine the size of liberation of run of mine and at which size of coal it should be crushed. Yield can be increased remarkably if decision of blending should be taken for these coals. Analysis of complex formulated study show that the value of critical specific gravity at $30 \mathrm{~mm}$ is 1.67 and at $11 \mathrm{~mm}$ is 1.56 which shows that at these values of specific gravities the separation is very difficult even by using gravity method as shown in Figure 4. Therefore washability index and NGMI could be more useful and shall help to determine the size of run of Mine coal and level clean coal with very less ash percentage can be produced from 2 or more crushing sizes.

Likewise Figure 4 shows the trends analysis for near gravity material index vs. clean coal ash \%. The range of clean coal ash percentage is between 16 to 34 and study shows that the trend is diverted more towards the range between 28 to 34 . Most of the trends are making points at 33 to 34 which are towards the end as seen in Figure 4.

\section{References}

[1] Wurst, H.B., Bachmann, J.F., Bachmann, C.C. and Cipold, M.P. (2013) Washability Monitor for Coal Utilizing Optical and X-Ray Analysis Techniques. Proceedings of 17th International Coal Preparation Conference, Istanbul, 1-6 October 2013, 2-3.

[2] Jha, G.S., Chattopadhyay, P.C., Prasad, P.S., Mitra, A.N., Maji, S.C., Gouri T. and Haldar D.D. (2010) Washability Studies and Characterization of Cleans of Coking Coal Sample from BCCL. Proceedings of the 11th International Seminar on Mineral Processing Technology (MPT-2010), Jamshedpur, 484-488.

[3] Mushtaq, F., Qadeer, A., Fahad, M. and Aftab, A. (2012) Coal Fired Power Generation Potential of Balochistan. Petroleum \& Coal, 54, 132-142.

[4] Lin, C.L., Miller, J.D., Luttre, U.G.H. and Adel, G.T. (2007) On-Line Washability Analysis for the Control of Coarse Coal Cleaning Circuits. High Efficiency Coal Preparation: An International Symposium, 32, 5-10.

[5] Latif, A., Ilham, D. and John, M. (1999) Advances in Coal Cleaning. Paper of American Patent, 3, 1-2.

[6] Majumder, A.K. and Barnwal, J.P. (2004) Development of a New Coal Washability Index. Minerals Engineering, 17, 93-96. http://dx.doi.org/10.1016/j.mineng.2003.10.005 
Scientific Research Publishing (SCIRP) is one of the largest Open Access journal publishers. It is currently publishing more than 200 open access, online, peer-reviewed journals covering a wide range of academic disciplines. SCIRP serves the worldwide academic communities and contributes to the progress and application of science with its publication.

Other selected journals from SCIRP are listed as below. Submit your manuscript to us via either submit@scirp.org or Online Submission Portal.
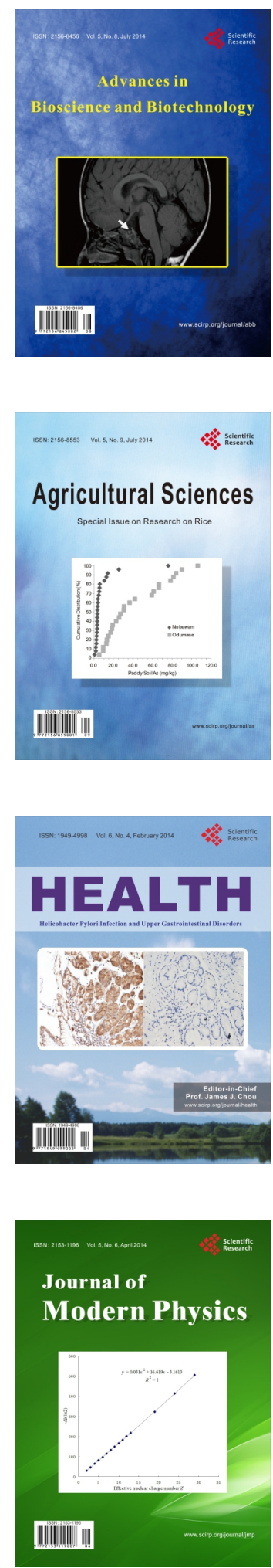
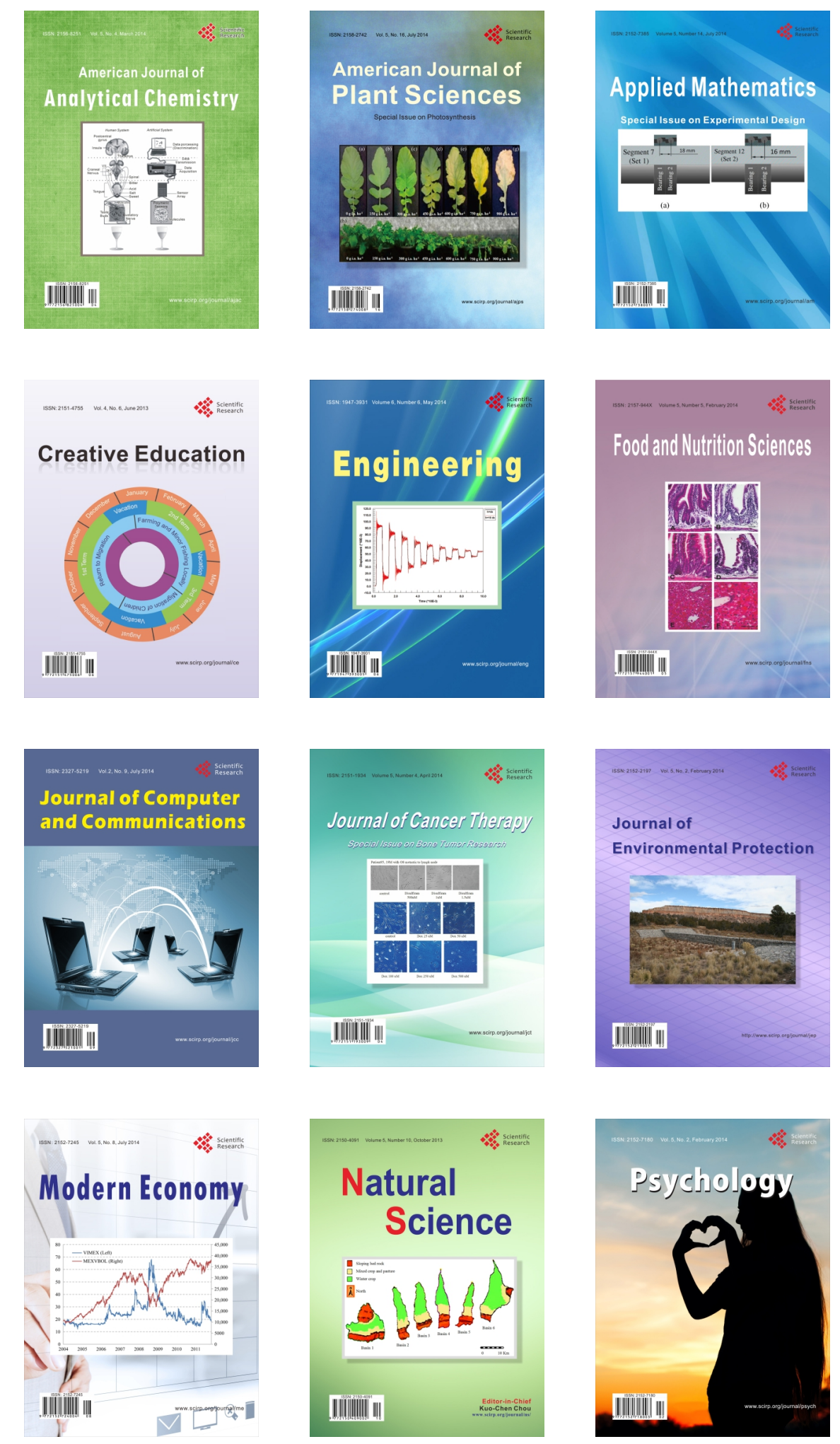